\title{
Personal Security and Cyberspace in Time Of COVID-19 Modes of Working
}

\author{
Ewa Matuska ${ }^{1 *}$, and Wojciech Piestrzynski ${ }^{1}$ \\ ${ }^{1}$ Pomeranian Academy, Chair of Management, 76-200 Slupsk, Poland
}

\begin{abstract}
The paper presents the analysis of the quantitative research examining the level of the sense of security and the cognitive satisfaction connected with the intense use of digital technology as the result of the switch into remote or hybrid modes of working, especially in a group of high skilled workers. The study was conducted during second wave of the Covid-19 pandemics on the sample $(\mathrm{N}=246)$ of Polish employees representing Millenials' generation. The online questionary was disseminated among employees until 30 age working in different sizes of enterprises (micro, SMEs and big ones), located in northern regions of Poland. The results have showed the moderately negative impact of the intensive cyberspace presence in connection with new modes of working for the personal sense of security of the respondents. The sense of security of respondents didn't correlate with cognitive satisfaction flying from digital mode work. The found results can be used as recommendations for introducing more holistic wellbeing hr practices in organizations and also for implementing new kinds of nonfinancial benefits in talent management programs.
\end{abstract}

\section{Introduction}

"(...) Technology destroys jobs, but not the job itself" [1].

The digital economy, a concept introduced in the mid1990s [2] is rapidly developing in 21 st century together with so-called 4.0 economy [3] and both imply fundamental changes in the world of organizations and workplaces. New technologies, such as artificial intelligence, automation, virtual and augmented reality, big data processing etc., are connected with the reduction of traditional job places and have the basic impact on the way, shape and forms of work as well as its valuation [4]. Scenarios of this impact, designed in different parts of the world, such as Asia, America, or Europe differ significantly, but all of them assume inevitable changes for both organizations and employees [5]. The expected impact of the digital technology is connected directly with labour costs, and indirectly with job places and earnings of employees. According to research already by 2030 is expected that about a third of man-hours can be replaced by intelligent machines [5]. However, the digital transformation of enterprises occurred to be problematic component of the overall digital transformation of the economy. Research conducted in 2018 by McKinsey on a sample of 1,793 representatives of companies from all over world revealed that "a successful digital transformation is more difficult than any a known type of organizational change" [6]. The feeling of subjective personal threat in the upcoming era of artificial intelligence is accompanied by numerous doubts perceived at the organizational, micro and macroeconomic level. Personal security is usually associated with a sense of stability, durability, certainty and lack of threats, both in the physical and mental sphere[7]. Obviously, the state of personal security perceived by employees influences not only their well- being but also readiness to meet new technological challenges, to effectively cope with new organizational stressors and to take proactive attitude towards efforts of own upskilling or reskilling.

Questions such as: how will the development of modern digital technologies affect the global economy, national or regional labour markets? - bother entrepreneurs and political decision-makers. For the individual employees more vital seem to be considerations how the automation of work changes the work organization in enterprises and the job demands. In that conditions fundamental questions arise: whether the technical development, which requires systematic investment in training new professional competences of employees operating automated production systems, eliminate the economic rent from automation? The future sociological and psychological consequences of the automation and robotization of work, analysed both on a macroeconomic, microeconomic and individual scale are equally important. The common question arises: will there be enough jobs in the future for everyone interested? Probably not, and it means tensions in the labour market, especially among young people entering employment and not posing valued digital competences. These concerns express the state of a sense of personal and organizational (in)security caused by the development of cybertechnology. The sense of security in literature is assumed as a state of internal balance resulting from having a sufficient, from the point of view of individual, level of own goal- 
oriented activity [7]. Recently, the anthropocentric approach to the issues of safety and security systematically displaces the old approaches focused on the security of the state, regions, etc. The main focus of anthropocentric concept of security situates the personal security, team security or organizational security within the area of security culture [8]. The contemporary analysis of the threats that affect human safety requires the identification of diverse cause-andeffect relationships in the complex postmodern reality, both material and non-material one. Authors of the article used this concept to plan own research. Deloitte's experts in the report „The voice of the European workforce" from the mid of 2020 [9] warn that although digital technology is a key, it should not be considered more important than the needs and expectations of the same employees, especially in hard time of ongoing global crisis suddenly started in 2020 together with Sars-Cov2 pandemics. This unexpected turn in economy and social life was created first of all via biological threat (fear about the health and the life) but that threat only strengthened the threat connected with the expectation of job lost [10]. The issue of realistic economic threats, data of bankruptcy, minimized economic activity of the companies representing variable sectors, or growing up rates of unemployment, are the core part of the contemporary economic studies. The conclusions are that pandemic is going to disrupt labor market at least as hard as economic crisis [11]. At the moment the less attention is paid on the problem of the occupational stress caused by the risk of COVID-19 and its possible, shortterm and long-term repercussions. However, the first observations and research data are collected also in that field, especially in the context of the new modes of working (flexible, remote, or hybrid work), threats of massive decruitment, challenges of using new digital tools, managing dispersed teams, etc.

From other side, pandemic hard time sped up the implementing of modern technologies in companies together with a remote (or hybrid) work mode commonly implemented by demand for social distancing [10]. All of it verified digital competences of employees, especially in a group of "knowledge workers" and caused their intensive professional development. The recent surveys done on the sample European workers show that people and their skills will play a critical role in overcoming the difficulties of adapting the workplace to the new, post-pandemic reality [10]. According to many sources the main forms of remote work are likely to persist long after COVID19 is finished [12]. That will require from the side of employers' new costs investments, both in hard digital infrastructure as well as in human capital development, in deepening and broadening IT skills of employees in different job places. However, such structural switch also generates different risks accentuating inequalities and creating new psychological and emotional stresses among employees, including from social isolation. The "Future of work model" designed for post pandemic reality [13] recommends to include the strategy based on both people and technologies. The main assumptions underlying this approach is wide concept of employees' well-being where economics and sense of personal and social security are interconnected [14]. The pandemic crisis threats employees economic and social safety in a massive way because creates the grand danger for their health and life perspectives. While some workers realize only minor changes when switching work to their home office, for many it means they cannot do their jobs like they used to do before. In fact, blurred borders between work and life during remote, or hybrid work model bring a lot of pitfalls for employee's well-being. Being at home office they loosing time and space structure which in a traditional mode of work allows clearly divide between time for work and for private life. Home stops to be asylum and a place for relax. It is now a space of imperfect work conditions. Job place at home office usually doesn't meet ergonomic requirements, even the space is usually not enough wide as has to be shared with other family members, also working remotely. These limitations, compounded with deprivation from wide social contacts and favourite activities, easily create new kind of physical and psychological threats for employees' subjective well-being. They activate depression symptoms development, burn-out syndrome or at least feelings of loneliness and sadness [15]. In a such way, the physical and psychosocial organizational security context disrupted by current coronavirus crisis determines not only economic survival, but also basic conditions for development of individuals and organizations [14].

Employees representing particular work generations obviously differ in their reception of the current crisis situation, as younger and elder people differ in their health and life risks in confrontation to get the coronavirus disease [16]. Already it is well proved that the risk for death and severe illness with COVID-19 is best predicted by age. The likelihood of death increases with age (sharply after age 50) among those who contract the virus in all countries where this has been examined [17]. That means COVID-19 threats are evident for elder people, including elder employees. Consequently, from that point of the view, the pandemic situation could be interpreted as less stressful for the young cohort of employees (Millenials) as they belong to the less risky cohorts. Moreover, they are better prepared to fill remote or hybrid work because usually have higher IT skills than older workers. But the interpretation can be done also in an opposite way - the new modes of work imposed by pandemic situation are the source of the high psychological stress especially for the young employees as they are very involved in real interpersonal relationships (thus, more suffer with social isolation) and till now hadn't experience with the economic crisis in their professional life.

\section{Cyberspace acceleration use in pandemic times}

One of the contemporary definitions of cyberspace recognizes it as "the space for processing and exchanging information created by ICT systems (...) 
together with the connections between them and relations with users."[18]. The activities of individuals and organizations in cyberspace consist reading, exchanging, modifying, and creating information. These operations are performed in the digital domain and require appropriate digital competences of the users. Also important are the mutual relations between systems and users, the two-sided connection of activities in cyberspace with activities in the "physical" reality (real world) and their mutual consequences (both positive, as well negative) [19]. The intensive use of cyberspace resources is a new dimension for human activities, enabling gathering large amount of data in one physical place, and processing them both for the implementation of task goals as well as for personal cognitive satisfaction. Proper acquisition, use and preservation of data resources become a priority not only in the effective management of organizations, but also in the effective fulfilment of daily employee's tasks at various workplaces. Data processing and interpreting creates the new information which becomes a value for the organization. The cyberspace and their opportunities fascinate especially young people who have usually sufficient digital skills for intensive use ICT channels in their social and professional networking. Working in pandemic reality substantially have increased their presence and operations in cyberspace.

The paper content has been conceptualized based on literature review and on the basis of the quantitative research via using non standardized questionary regarding the personal security and cognitive satisfaction [7].

1. Does the experience of pandemic working modes influencing the personal sense of security of young employees?

2. Is the intensive operating in a cyberspace in conditions of remote or hybrid work modes perceived as cognitively attractive and personally secure?

The above research questions inspired own authors' research dedicated to explore the issue how the intensive cyberspace activity caused by implementing remote, flexible or hybrid work modes is perceived by young employees in COVID-19 pandemic work circumstances. Exactly: in which way (if at all) new kinds of work connected with prolonged exploration of cyberspace and virtual reality influences selfevaluation of Millenials' well-being in terms their sense of security and cognitive satisfaction.

\section{Research Design, Results and Discussion}

The authors' first research assumption was that stressful work context implemented together with COVID-19 demanding for social isolation is perceived by young employees as a kind of personal oppression. Thus, it is reflected in the lower (than the average) level of their perceived sense of security regardless of the size of the organization they are working for (research hypothesis no 1). From the other side, as young people usually have sufficient IT skills and were born together with the Internet, they should value the possibility to spend more time in the cyberspace. The new modes of working should deliver them cognitive satisfaction and by thus way - positively moderate perceived level of their sense of security (research hypothesis no 2).

The study was conducted in a second half of Nov. 2020 when COVID-19 pandemics restrictions in Poland were again more strict and companies continued their mostly digitally based modes of working. The online questionary was disseminated among randomly selected sample $(\mathrm{N}=246)$ of employees until 30 age, representing different sizes of enterprises (micro, SMEs and large ones), located in northern regions of Poland (Pomeranian and West Pomeranian regions). The size of the company was determined on the basis of the number of people employed (up to 10 - micro-company, up to 50 - small company, up to 250 - medium company, over 250 large company). The descriptive statistics of the sense of security for examined employees of the three groups of company sizes (A, B, C) are shown in Table1.

Table 1. Respondents self-evaluation regarding their level of sense of security*

\begin{tabular}{|c|c|c|c|}
\hline $\begin{array}{c}\text { Enterprise } \\
\text { size }\end{array}$ & $\begin{array}{c}\text { Number } \\
/ \mathbf{N}\end{array}$ & $\begin{array}{c}\text { Median } \\
/ \mathbf{M}\end{array}$ & $\begin{array}{c}\text { Standard } \\
\text { Deviation } \\
\text { /SD }\end{array}$ \\
\hline $\begin{array}{c}\text { Micro and } \\
\text { small (A) }\end{array}$ & 87 & 3,52 & .96 \\
\hline $\begin{array}{c}\text { Medium } \\
\text { (B) }\end{array}$ & 99 & 3.35 & 1,03 \\
\hline Large (C) & 60 & 3.43 & .83 \\
\hline
\end{tabular}

Source: own elaboration

Considering the phenomenon of examined level of the sense of security among young employees, it should be emphasized that there were not discovered statistical differences in their intensity in the studied subgroups representing different size of workplaces. However, it also has to be remarked that all subgroups revealed at best moderate level of security, what is indicated by their median rates (M87= 3,52 ; $\mathrm{M} 99=3,35$, M60=3,43). The final picture of this phenomenon checked as analysis of variances of results delivered by the three investigated subgroups is justified as nonsignificant $(\mathrm{F}=.76$ and $\mathrm{p}=.46)$. It is showed in a Table $2 \mathrm{a}$.

Table 2a. ANOVA of the sense of security of employees in different size companies referred to intense use of digital mode of working

\begin{tabular}{|c|c|c|c|c|}
\hline $\begin{array}{c}\text { Source of } \\
\text { variance }\end{array}$ & SS & df & MS & Test F \\
\hline $\begin{array}{c}\text { Between } \\
\text { subgroups } \\
(\mathrm{A}, \mathrm{B}, \mathrm{C})\end{array}$ & 1.42 & 2 & .71 & .76 \\
\hline $\begin{array}{c}\text { Inside of } \\
\text { subgroups } \\
(\mathrm{A} / \mathrm{B} / \mathrm{C})\end{array}$ & 225.03 & 243 & .92 & \\
\hline
\end{tabular}




\begin{tabular}{|c|c|c|c|c|}
\hline Sum & 226.45 & 245 & & \\
\hline
\end{tabular}

$\mathrm{p}=.46$

Source: own elaboration

When looking for answers to what pairs' treatments contributed to the above overall result, the post hoc Tukey test was used, but again no significant differences in the level of sense of security were established employees representing different size of companies (see Table 2b).

Table 2b. Post hoc Tukey's test for respondents' sense of security in different pairs of company size*

\begin{tabular}{|c|c|c|c|}
\hline Pair & $\begin{array}{c}\text { Tukey's } \\
\text { statistics } \\
\text { HSD Q }\end{array}$ & $\begin{array}{c}\text { p values of } \\
\text { Tukey's } \\
\text { HSD Q }\end{array}$ & p \\
\hline (A)versus (B) & 1.75 & .43 & Nonvalid \\
\hline $\begin{array}{c}\text { (A)versus } \\
\text { (C) }\end{array}$ & .83 & .80 & Nonvalid \\
\hline $\begin{array}{c}\text { (B)versus } \\
\text { ( C) }\end{array}$ & .71 & .85 & Nonvalid \\
\hline
\end{tabular}

Source: own elaboration

The above results basically confirm the assumptions of the first hypothesis (h1). The employees of the three investigated groups of company sizes did not significantly differ in the level of their perceived sense of security and they revealed the similar - moderate level of that subjective well-being measure. The expected negative (stressful) impact of the distant working modes occurred to be evident. However, the new working conditions have influenced the well - being of respondents as they didn't evaluate their sense of security on a high or a very high level, only on an average, or moderate level. The second research question was that maybe, the opportunity to spend more time in a virtual world compensate the social deprivation caused by pandemic situation? That question has referred to the possible correlations between personal sense of security and the cognitive attractiveness of the intense operating in cyberspace when filling work tasks. It was the topic of verification of research hypothesis number 2 . The results obtained for that issue show Table $3 \mathrm{a}$ and Table $3 \mathrm{~b}$.

Table 3a. ANOVA of the sense of security of employees of different size companies referred to the cognitive satisfaction with digital mode of working

\begin{tabular}{|c|c|c|c|c|}
\hline $\begin{array}{c}\text { Source of } \\
\text { variance }\end{array}$ & SS & df & MS & $\begin{array}{c}\text { Test } \\
\text { F }\end{array}$ \\
\hline $\begin{array}{c}\text { Between } \\
\text { subgroups } \\
(\mathrm{A}, \mathrm{B}, \mathrm{C})\end{array}$ & 0.06 & 2 & .03 & .03 \\
\hline $\begin{array}{c}\text { Inside of } \\
\text { subgroups } \\
\text { (A/B/C) }\end{array}$ & 225.94 & 243 & 1.04 & \\
\hline Sum & 253.00 & 245 & & \\
\hline
\end{tabular}

$\mathrm{p}=.97$

Source: own elaboration

The general result of the analysis of variance for the variable: "the cognitive value of the intensive use of cyberspace in a new, pandemic work modes" - turned out to be irrelevant $(\mathrm{F}=.03$ and $\mathrm{p}=.97)$.

When looking for answers to what pairs' treatments contributed to the above overall result, again the post hoc Tukey test was used but no significant differences in the level of cognitive satisfaction in different subgroups of company size were found (see Table $3 b$ ).

Table 3b. Post hoc Tukey's test for respondents' sense of security in different pairs of company size*

\begin{tabular}{|c|c|c|c|}
\hline Pair & $\begin{array}{c}\text { Tukey's } \\
\text { statistics } \\
\text { HSD Q }\end{array}$ & $\begin{array}{c}\text { p values of } \\
\text { Tukey's } \\
\text { HSD Q }\end{array}$ & p \\
\hline (A)versus (B) & .03 & .89 & Nonvalid \\
\hline $\begin{array}{c}\text { (A)versus } \\
\text { (C) }\end{array}$ & .28 & .89 & Nonvalid \\
\hline $\begin{array}{c}\text { (B)versus } \\
\text { ( C) }\end{array}$ & .32 & .89 & Nonvalid \\
\hline
\end{tabular}

Source: own elaboration

The answer for the posted second research question is as follow: the new working modes imposed by pandemic conditions in a similar, moderately positive way, influence the perceived cognitive value flying from intensive contact with cyberspace among young employees regardless of the size of the company they are working for. However, the both studied variables the sense of security and the sense of cognitive satisfaction in connection with new working conditions in a pandemic - turned out to be independent of each other. Summing - the obtained results doesn't implicate that expected cognitive value flying from intensive operating in a cyberspace in remote (or hybrid) mode of working compensate the young employees' slightly decreased sense of security.

\section{Conclusion}

The pandemic situation forcing employers to organize the work in a way to meet requirements of social isolation evolved the new forms of delivering work tasks. The most characteristic include the remote work and the hybrid work. Employees, from other side, had been confronted with the demand for a rapid adaptation to new work modes without the time for necessary preparation. Employers' usually didn't offer them special upskilling programs in digital technologies, nor dedicated change management programs. Thus, the employees had to manage themselves to new circumstances and quickly learn new behavioural patterns connected with jobs. Very fast the SarsCov2 disease occurred to be to the new kind of severe biological threat, and, in the same time, an important psychosocial organisational stressor. This agent is still 
aggressively acting on a global scale, with high speed of spread and, till now - without the definite deadline. Covid-19 crisis have revealed the key barrier in effective organizational activity. It occurred to be the lack of intense social interaction and face to face direct communication during implementing job tasks.

The Covid-19 situation created also new stressors for managers. They had to answer questions like for example: how to effectively manage dispersed teams? or how to support subordinates suffering with social isolation working in home offices? Current crisis is challenging both regular employees as managers. Confronting them with problem of lower motivation and engagement caused by pessimistic mood or by the feel being overloaded. Home office work stopped to be perceive as desirable benefit as it was forced by formally introduced restrictions. People who are pressed to stay at home long time easily fall into a state of discouragement, depression, losing their long- term goal orientation. Suffering with low mood, are less creative, less resistant for overcoming different obstacles and problem solving. Are not able effectively plan or implement own professional careers.

However, after close to one year of the pandemic crisis existence, it can be concluded that this abnormal situation creates also a kind of paradox opportunities, both for organizations as well for employees. Organizations have to redefine own business strategies being focused on searching for the possible new "lean" solutions and cutting costs. They have to meet new kinds of organizational and strategic management challenges, learn new patterns of leaderships. Employees have the chance for to checking and updating their digital competences, maybe even have to decide for reskilling. They collecting new kind of employee experience - the possibility to feel satisfaction with the intense using cyberspace during implementing their work tasks. That all create the new kind of the positive professional challenge which can make wider their careers options.

Summing up, the switch into the new, remote or hybrid modes of work, especially in case of high skilled job places, creates both threats and challenges, as well as new opportunities. For the same employees as well as for organizations. From the point of the view of individual employee it generates the new kind of psychosocial work-related stress which can activate the set of negative effects for his physical and psychical health. It is necessary that this new category of work connected risk should be included into the work safety and hygiene factors monitored and controlled by organization. It seems to be very important especially that as the new modes of work are predicted to stay as the new stable forms of work organization also in the post-covid times. Thus, companies have to consider how to enhance the well- being of their workforce, not only in a current pandemic times but also after crisis. In an investigated sample of the young employees, representing Millennial generation, the personal sense of security occurred to be on a moderate level and was not connected with the cognitive satisfaction expected because of the intensive work digital activity. This result confirms that the new modes of work are not neutral for the emotional and motivational psychical sphere of employees. They influence their subjective sense of security.

What is especially important from the side of management - the obtained results didn't differ in relation to the size of the workplace. It means, both big corporations as well as small and medium enterprises have to be aware how the new work conditions influence the well - being of their skilled employees. All sizes and types organizations have to rethink own talent management strategies and implement the new non-financial types of benefits. Today the flexible work modes including remote work or hybrid work are not benefits anymore. Necessary is to substitute them with the new proposals to gain the competitive position from attracting talents. Managers have to especially care about most effective, high skilled employees who positively verified their competences working according to new rules of distant work. And many of them probably recognized also new attractive career possibilities on fast changing labour market.

\section{References}

1. Technology and the American economy: Report of the National Commission on Technology, Automation, and Economic Progress, US Department of Health, Education, and Welfare, Feb. 1966.

2. Tapscott D., The digital economy: promise and peril in the age of networked intelligence. New York: McGraw-Hill, 1995

3. Hermann M., Pentek T., Otto B.,: Design Principles for Industrie 4.0 Scenarios, working Paper, 01/2015, http://www.snom.mb.tu dortmund.de/cms/de/forschung/Arbeitsberichte/De sign-Principles-for-Industrie-4_0-Scenarios.pdf [accessed 15.12.2020]

4. Harari Y.N., 21 lekcji na XXI wiek (eng. 21 lessons for the 21st century), Publ. Wydawnictwo Literackie, Kraków 2018.

5. Manyika J, Lund S., Chui M., Bughin J., Woetzel J., Batra P., Ko R., Sanghvi S., What the future of work will mean for jobs, skills, and wages, Mc Kinsey Global Institute, Dec 2017, online: www.mckinsey.com [accessed 10 Dec. 2020]

6. McKinsey \&Company, Unlocking success in digital transformations, McKinsey 2018, www.mckinsey.com [accessed 12 Dec. 2020]

7. Klamut, R. Two-factor model of safety experience. Theoretical assumptions and empirical verification: Safety Experience Questionnaire, Polish Psychological Forum, t. 24, no 3, 2019, p. 308-323.

8. Sokołowski, M. The concept and the essence of personal security, Kultura Bezpieczeństwa. Nauka - Praktyka - Refleksje, 2019, no 33, p. 117-130.

9. W. Gosling, M. Coppola, K. McCarthy, May the workforce be with you: The voice of the European workforce 2020, Deloitte Insights, online [accessed 12 Jan. 2021] 
10. K. Pouliakas, J. Branka, EU jobs at highest risk of COVID-19 social distancing: Will the pandemic exacerbate labour market divide?", IZA DP No. 13281, May 2020.

11. https://www.eurofound.europa.eu/publications/blo $\mathrm{g} /$ coronavirus-a-labour-marketearthquake(accessed: 8.01.2021)

12. S. Lund, A Madgavkar, J. Manyika, S. Smit, What's next for remote work: An analysis of 2,000 tasks, 800 jobs, and nine countries, McKinsey Global Institute, Nov. 2020. www.mckinsey.com [accessed 18 Dec. 2020].

13. E. Volini,J. Schwartz, B. Denny, D.Mallon, Y. van Durme, M. Hauptmann, R. Yan, S. Poynton, Returning to work in the future of work, Deloitte Insights, May 2020 , online [acessed 7.Jan 2021]

14. Webb, D., Wills-Herrera, E. Introduction [in:] D. Webb and E. Wills-Herrera (eds.), Subjective Well-Being and Security, 1 Social Indicators Research Series 46, Springer Science + Business Media B.V. 2012.

15. Henning-Smith, C.(2020). COVID-19 poses an unequal risk of isolation and loneliness. Retrieved April 10, 2020. [ accessed 23.11.2020 from https:/thehill.com/opinion/healthcare/488215covid-19-poses-an-unequal-risk-of-isolation-andloneliness].

16. https://osha.europa.eu/en/highlights/coronavirusdisease-covid-19-outbreak-and-workplace-safetyand-health [accessed: 05. 02. 2021]

17. Crimmins, E. Age-Related Vulnerability to Coronavirus Disease 2019 (COVID-19): Biological, Contextual, and Policy-Related Factors, Public Policy \& Aging Report, Volume 30, Issue 4, 2020, p.142-146

18. Cyberspace Protection Policy of the Republic of Poland, Ministry of Administration and Digitization, Internal Security Agency, Warsaw 2013.

19. Carnevale,J.B., Hatak, I., Employee Adjustment and Well-Being in the Era of COVID-19: Implications for Human Resource Management, Journal of Business Research, May 2020. DOI: 10.1016/j.jbusres.2020.05.037 